\title{
AMMI Analysis for Aluminium Tolerance on Seedling Parameters of Indigenous Rice Genotypes from Manipur
}

\author{
Kanala Sai Sreelekha*, E. V. D. Sastry, M. Prapakaran and Danisa Dube \\ Department of Genetics and Plant Breeding, College of Agriculture, \\ CAU, Imphal - 795004, India \\ *Corresponding author
}

\begin{abstract}
A B S T R A C T
Aluminium (Al) toxicity is the major limiting factor of crop production in acidic soils. Most of the soils in North eastern region are acidic. In order to improve the crop production in acidic soil conditions, screening genotypes which are tolerant to aluminium induced stress would be immense importance. Besides this finding the genotypes which are stable at different aluminium levels with high mean is equally important. The present investigation was aimed to identify stable promising genotypes with high seedling fresh and dry weights and to determine the environment which is highly influencing the genotypes. Twenty randomly selected local genotypes of rice were evaluated for at six concentrations of Al toxicity $(25 \mu \mathrm{M}, 50 \mu \mathrm{M}, 75 \mu \mathrm{M}, 100 \mu \mathrm{M}, 125 \mu \mathrm{M}, 150 \mu \mathrm{M})$ created by $\mathrm{AlCl}_{3}$ along with control $(0 \mu \mathrm{M})$ in Hoagland solution in plant growth chamber at department of Genetics and Plant breeding, Central agricultural University, Imphal, Manipur. Pooled analysis of variance (ANOVA) based on seedling fresh weight and dry weight was conducted to determine the effects of genotype, environment and their interactions $(\mathrm{G} \times \mathrm{E})$. The performance of rice genotypes under different $\mathrm{Al}$ levels were assessed using AMMI analysis. Among the rice genotypes RCM-6 (G2), ChakaoPoireiton (G11), RCM-12 (G6), Tungou (G3), Keibiphou (G15), CAU-R1 (G20) were in general less affected by aluminium levels, while RCM-10 (G10), RCM-5 (G9) and Sangsangba (G1) were relatively sensitive to aluminium levels. As per AMMI 2 biplot Keibiphou (G15), ChakaoPoireiton (G11), Pat phou (G16) were near the origin hence those are stable genotypes.
\end{abstract}

\section{Keywords}

Aluminium stress, AMMI biplots, GXE interaction

\section{Article Info}

Accepted:

12 August 2020 Available Online: 10 September 2020

\section{Introduction}

Rice is the most dominant and staple food crop grown in Manipur. The crop is cultivated in an area of 51 thousand hectares, with production of 176.80 thousand metric tonnes. The productivity of Rice in Manipur is 3.47 metric tonnes / hectare (Department of Agriculture, Government of Manipur, 2019).
In North eastern hill region about 21million ha of acid soils are found, of which (2.19Mha) acidic soils are found in Manipur. Aluminium (Al) toxicity is the major limiting factor of crop production in acidic soils. Soil acidity, associated infertility and mineral toxicities are major constraints to agricultural production in several parts of the world. In response to aluminium stress, roots 
become stubby and brittle. The root tips and lateral roots thicken and turn brown. Such aluminium injured roots become inefficient in absorbing nutrients, water and the root system as a whole gets affected with many stubby lateral roots and no fine branching. Consequently, plants become susceptible to various stresses especially drought (PariascaTanaka et al., 2009). Off the several promising approaches such as adding exogenous chemicals to soil, crop rotation, increasing soil acidity by liming, etc., breeding and advanced root phenotyping tools to identify Al-tolerant cultivars appears to be the most promising strategy (Rao et al., 2016).

Besides identifying tolerant genotypes, it is very important to determine the $G \times E$ interactions because the characters are generally quantitative, they are highly influenced by the environment. Among the several methods to estimate stability of the genotypes, AMMI analysis is most widely exploited in different crops for the identification of stable genotypes over locations. The results of AMMI (Additive Main Effects and Multiplicative Interaction) analysis are useful in identifying the stable genotypes to specific environments which can be utilized in breeding program. The AMMI model fist calculates genotypes and environment additive (main) effects using analysis of variance (ANOVA) and then analyses the residual from this model (namely the interaction) using principal components analysis (PCA).Thus, AMMI model is a hybrid model (Gauch, 1993). The analysis not only serves an estimate of the total $G \times E$ interaction effect of each genotype but further partitions it into the environmental effects due to the interaction of the individual (Ebdon and Gauch, 2001).

Therefore, the main objective of current research work was to identify stable promising genotypes with high seedling fresh and dry weights and to determine the environment which is highly influencing the genotypes.

\section{Materials and Methods}

The present investigation was carried out in plant growth chamber at the department of Genetics and Plant Breeding, College of Agriculture, Central Agricultural University, Imphal, Manipur, using twenty randomly selected local genotypes of rice. These genotypes were evaluated for their seedling characters at six concentrations of Al toxicity (25 $\mu \mathrm{M}, 50 \mu \mathrm{M}, 75 \mu \mathrm{M}, 100 \mu \mathrm{M}, 125 \mu \mathrm{M}$, $150 \mu \mathrm{M})$ created by $\mathrm{AlCl}_{3}$ along with control $(0 \mu \mathrm{M})$ in Hoagland solution. Each genotype was evaluated at each concentration in three replications. The seed were sown in paper towels using BP method. The experiment was conducted in germination chamber set at $25^{\circ}$ $\mathrm{C}$ under16/8 h light/dark duration for 21 days. From the correlations studies among all the seedling characters like germination $\%$, speed of germination, shoot length, root length, seedling length, fresh weights and dry weights of shoot, root and seedlings indicated that seedling fresh weight and dry weights were found to be highly correlated with all the other traits and because they represent the growth of the plant at the seedling stage, these two traits were taken for AMMI analysis.

\section{Statistical analysis}

AMMI (Additive main effects and multiplicative interaction) model combines univariate technique (ANOVA) for the main effects and multivariate technique (PCAprincipal component analysis) for genotypeenvironment interaction (Gauch, 1988; 1992). Gauch and Zobel (1996) compared the performance of AMMI analysis with ANOVA approach and regression approach and found that ANOVA fails to detect a significant 
interaction component and regression approach accounts only a small portion of the interaction sum of squares only when the pattern fits a specific regression model.

The AMMI model for $\mathrm{T}$ genotypes and $\mathrm{S}$ environment is given as:

$\mathbf{Y i j}=\mu+\mathrm{gi}+\mathbf{e j}+\sum_{n-1}^{n} \lambda_{n} \boldsymbol{\alpha}_{\mathrm{in}} \gamma_{\mathrm{jn}}+\boldsymbol{\theta}_{\mathrm{ij}}$

Where, ${ }^{\text {Yij is }}$ mean yield of the ith genotype in the jth environment, $\mu$ is general mean gi is the $i$ th genotypic effect, $e_{j}$ is $j^{\text {th }}$ location effect, $\lambda_{n}$ is eigen value of PCA axis $n, \alpha_{i n}$ and $\gamma_{j n}$ is ith genotype jth environment PCA scores for the PCA axis $n, \theta_{i j}$ residual, $n$ is number of PCA axis retained in the model. ANOVA and Stability analysis for seedling fresh weight ad seedling dry weight were carried out using AMMI analysis in PB Tools 1.4 version IRRI software.

\section{Results and Discussion}

\section{Analysis of variance}

The pooled analysis of variance for seedling fresh weight and dry weights is presented in the Error! Reference source not found.. It showed that mean sum of squares due to genotypes, aluminium levels and genotype $x$ environment interaction was significant for the 2 characters evaluated under present investigation. The partitioning of the $\mathrm{G} \times \mathrm{E}$ interaction into different IPCA components indicated that the total variation was explained by two IPCA components. Of this, IPCA1 explained more than $90 \%$ of the variation and the IPCA2 explained around 2$5 \%$. In general, the residual component was very less. Hence, AMMI analysis was concentrated on IPCA1 and IPCA2 models. Several authors also reported in various crops that first IPCA score has explained significant and greater percentage of GXE interaction (WondeAbera and Labuschagne, 2005, on maize; Farshadfar, 2008, on bread wheat).

\section{AMMI 1 Biplot for seedling fresh weight}

In AMMI model the contribution of each genotype and each environment to the GEI is assessed by use of the biplot graph display in which yield means are plotted against the scores of the IPCA1 (Zobel et al.,1988). AMMI1 biplot (

Fig.1) indicated that $\mathrm{A} 0(0 \mu \mathrm{M})$ was the most favourable for all the genotypes while the $\mathrm{A} 6(150 \mu \mathrm{M})$ was found to be least favourable environments for the character expression. Perusal of the figure also indicates that the aluminium levels linearly differentiated in their effect on the genotypes.

Genotypes (or environments) with large IPCA 1 scores (either positive or negative) have high interactions, whereas genotypes (or environments) with IPCA 1 scores near zero have small interactions (Crossa, Gauch, \& Zobel, 1990). AMMI1 biplot analysis depicted that the genotypes namely, RCM-10 (G10), Sangsangba (G1), RCM-11 (G18) were having highest seedling fresh weight than the average value and positive IPCA1 scores, while the genotypes Tungou (G3) and Leimaphou (G12) shown lower seedling fresh weight than the average and positive IPCA1 scores. In contrast, genotypes RCM-5 (G9), RCM-7 (G7), ChakaoPoireiton (G11), RCM12 (G6) were having highest seedling fresh weight than mean and negative IPCA1 scores, while the genotypes CAU-R1 (G20), RCM-13 (G15), RCM-6 (G2), Keibiphou (G14), RCM4 (G4), Pat phou (G16), Asangbakakra (G19), Malmalsang (G17), Moirang (G13), CAU-R3 (G5), Kio phou (G8) were with lower seedling fresh weight and negative IPCA1 scores (

Fig.1).

Genotype RCM-10 (G10) had highest positive IPCA1 values followed by RCM-11 (G18) 
and Moirang (G13) had highest negative IPCA1 values followed by CAU-R3 (G5) indicating least stability of these genotypes to seedling fresh weight. The genotype Sangsangba (G1) had higher than the average seedling fresh weight and least deviation from IPCA score zero, so it was regarded as most stable genotype with higher seedling fresh weight followed by ChakaoPoireiton (G11) and RCM-12 (G6).

Table.1 The pooled analysis of variance for seedling fresh weight and dry weights

\begin{tabular}{|l|c|c|c|c|c|}
\hline & \multicolumn{3}{l|}{ Seedling fresh weight } & \multicolumn{2}{l|}{ Seedling dry weight } \\
\hline Source & DF & \multicolumn{2}{|l|}{ MSS } & $\begin{array}{l}\text { Variation } \\
\text { explained } \\
(\%)\end{array}$ & \multicolumn{2}{l|}{ MSS } & $\begin{array}{l}\text { Variation } \\
\text { explained } \\
(\%)\end{array}$ \\
\hline Total & 419 & $20069^{* *}$ & & $161.5^{* *}$ & \\
\hline Environments (Alu) & 6 & $363065.753^{* *}$ & 26.08 & $3486.824^{* *}$ & 31.68 \\
\hline Genotypes & 19 & $289591.082^{* *}$ & 65.88 & $1943.273^{* *}$ & 55.92 \\
\hline G $\times$ E Interaction & 114 & $5884.255^{* *}$ & 8.03 & $71.766^{* *}$ & 12.39 \\
\hline IPCA 1 & 24 & $25819^{* *}$ & 92.4 & $321.9^{* *}$ & 94.4 \\
\hline IPCA2 & 22 & $1649^{* *}$ & 5.4 & $10.3 *$ & 2.8 \\
\hline Residuals & 68 & 219 & 2.2 & 3.4 & 2.7 \\
\hline Pooled error & 266 & 196.55 & & 5.78 & \\
\hline
\end{tabular}

* denotes $5 \%$ levels of significance, ${ }^{* *}$ denotes $1 \%$ levels of significance

Fig.1 AMMI biplot 1 for seedling fresh weight Fig 2 AMMI biplot 2 for seedling fresh weight
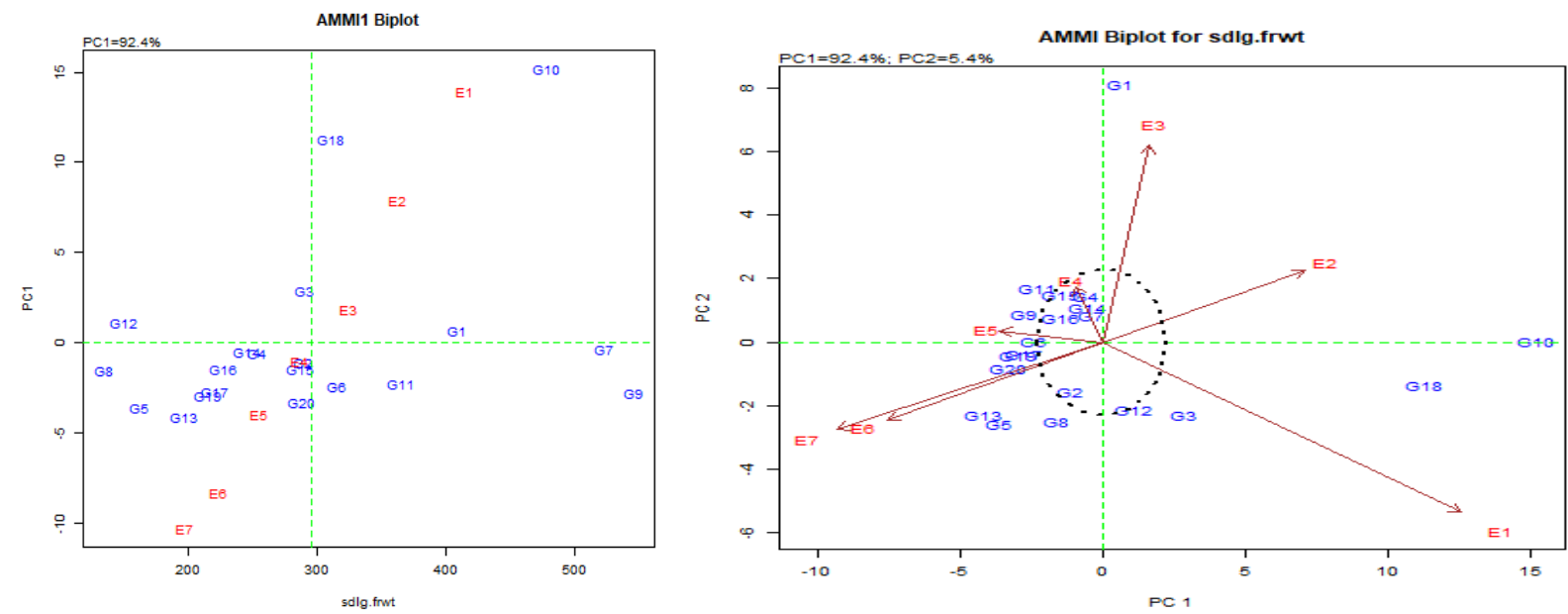

Genotypes: G1 = Sangsangba, G2 = RCM-6, G3 = Tungou, G4 = RCM-4, G5 = CAU-R3, G6 = RCM-12, G7 = RCM-7, G8 = Kio pho, G9 = RCM-5, G10 = RCM-10, G11 = ChakaoPoireiton, G12 = Leimaphou, G13 = Moirang, G14 = Keibiphou, G15 = RCM-13, G16 = Pat phou, G17 = Malmalsang, G18 = RCM-11, G19 = Asangbakakra, $\mathrm{G} 20=\mathrm{CAU}-\mathrm{R} 1$.

Environments: $\mathrm{E} 1=\mathrm{A} 0, \mathrm{E} 2=\mathrm{A} 1, \mathrm{E} 3=\mathrm{A} 2, \mathrm{E} 4=\mathrm{A} 3, \mathrm{E} 5=\mathrm{A} 4, \mathrm{E} 6=\mathrm{A} 5, \mathrm{E} 7=\mathrm{A} 6$. 
Fig.3 AMMI biplot 1 for seedling dry weight

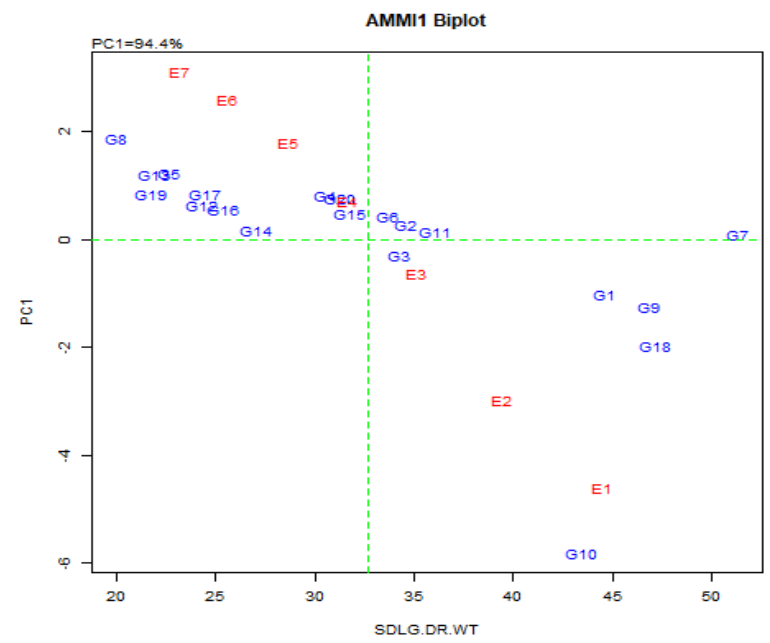

Fig.4 AMMI biplot 2 for seedling dry weight

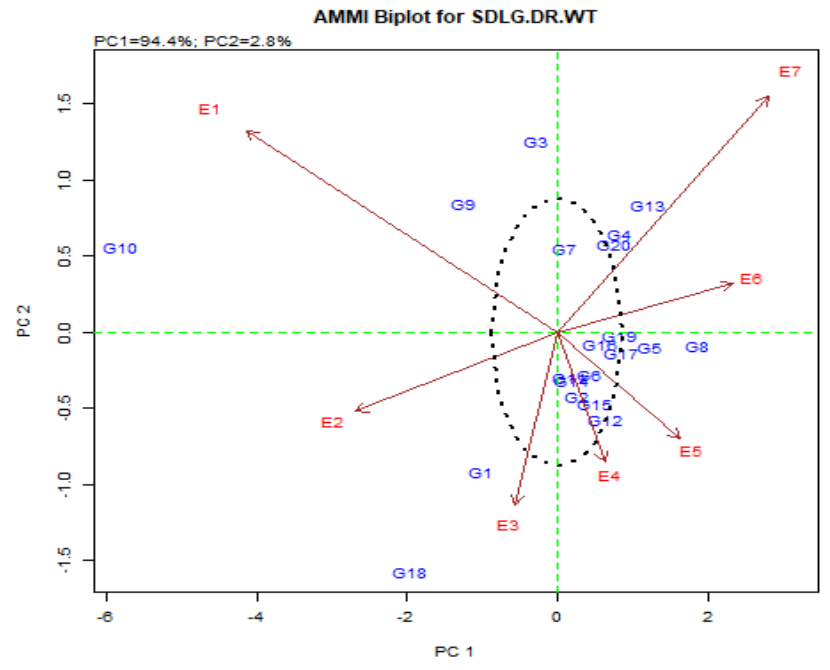

Genotypes: G1 $=$ Sangsangba, G2 $=$ RCM-6, G3 = Tungou, G4 = RCM-4, G5 = CAU-R3, G6 $=$ RCM12, G7 = RCM-7, G8 = Kio pho, G9 = RCM-5, G10 $=$ RCM-10, G11 $=$ ChakaoPoireiton, G12 = Leimaphou, G13 = Moirang, G14 = Keibiphou, G15 = RCM-13, G16 = Pat phou, G17 = Malmalsang, G18 = RCM-11, G19 = Asangbakakra, G20 = CAU-R1.

Environments: $\mathrm{E} 1=\mathrm{A} 0, \mathrm{E} 2=\mathrm{A} 1, \mathrm{E} 3=\mathrm{A} 2, \mathrm{E} 4=\mathrm{A} 3, \mathrm{E} 5=\mathrm{A} 4, \mathrm{E} 6=\mathrm{A} 5, \mathrm{E} 7=\mathrm{A} 6$.

\section{AMMI 2 Biplot for seedling fresh weight}

The AMMI2 biplot was generated using genotypes and environments scores of the first two IPCA and presented as (Fig. 2) to explain the relative magnitude of $\mathrm{G} \times \mathrm{E}$ interaction for specific genotypes and environments. The most accurate model for AMMI can be predicted by using the first two PCAs (Gauch and Zobel, 1996). Sites with short spokes do not exert strong interactive forces. Those with long spokes exert strong 
interaction (TaddesseLakew et al., 2017). The environment A1 $(25 \mu \mathrm{M}), \mathrm{A} 3(75 \mu \mathrm{M})$ and $\mathrm{A} 4$ $(100 \mu \mathrm{M})$ had short spoke they did not exerted strong interaction while the environments A0 $(0 \mu \mathrm{M}), \mathrm{A} 2(50 \mu \mathrm{M}), \mathrm{A} 5(125 \mu \mathrm{M})$ and $\mathrm{A} 6$ $(150 \mu \mathrm{M})$ exerted strong interactive forces. Genotypes RCM-7 (G7), Keibiphou (G14), Pat phou (G16), RCM-4 (G4), RCM-5 (G9), RCM-13 (G15) and ChakaoPoireiton (G11) were near the origin were non-sensitive to environmental interactive forces and showed wide stability whereas genotypes Sangsangba (G1), RCM-10 (G10) and RCM-11 (G18) were fell away far from the origin hence those are unstable genotypes. Sangsangba (G1) specifically adapted to A4 $(100 \mu \mathrm{M})$. As per both AMMI1 and AMMI2 biplot RCM-7 (G7) and RCM-5 (G9) were stable genotypes with highest seedling fresh weight.

\section{AMMI 1 Biplot for seedling dry weight}

The genotypes namely, RCM-7 (G7), ChakaoPoireiton (G11), RCM-6 (G2) and RCM-12 (G6) were having highest seedling dry weight than the average value and positive IPCA1 scores, while the genotypes RCM-13 (G15), CAU-R1 (G20), RCM-4 (G4), Keibiphou (G14), Pat phou (G16), Leimaphou (G12), Malmalsang (G17), Asangbakakra (G19), Moirang (G13), CAUR3 (G5) and Kio phou (G8) shown lower seedling dry weight than the average and positive IPCA1 scores. In contrast, genotypes RCM-11 (G11), RCM-5 (G9), Sangsangba (G1), RCM-10 (G10) were having highest seedling weight than mean and negative IPCA1 scores, no genotypes were observed with lower seedling fresh weight and negative IPCA1 scores (Fig. 3).

Genotype Kio phou (G8) had highest positive IPCA1 values followed by CAU-R3 (G5) and RCM-10 (G10) had highest negative IPCA1 values followed by RCM-11 (G18) indicating least stability of these genotypes to seedling dry weight. The genotype ChakaoPoireiton (G11) had higher than the average seedling dry weight and least deviation from IPCA score zero, so it was regarded as most stable genotype with higher seedling dry weight followed by RCM-6 (G2) and Tungou (G3).

Similar to seedling fresh weight, the aluminium levels also showed linear differentiation. A2 $(50 \mu \mathrm{M})$ and $\mathrm{A} 3(75 \mu \mathrm{M})$ showed least affect, while the $\mathrm{A} 0(0 \mu \mathrm{M})$ and $\mathrm{A} 6(150 \mu \mathrm{M})$ were the extreme.

\section{AMMI 2 Biplot for seedling dry weight}

The AMMI2 biplot for seedling dry weight represented IPCA1 and IPCA2 scores of $\mathrm{G} \times$ $\mathrm{E}$ interactions (Fig. 4). The environment A2 $(50 \mu \mathrm{M}), \mathrm{A} 3(75 \mu \mathrm{M})$ and $\mathrm{A} 4(100 \mu \mathrm{M})$ had short spoke they did not exert strong interaction while the environments $\mathrm{A} 0(0 \mu \mathrm{M})$ and A6 $(150 \mu \mathrm{M})$ exerted strong interactive forces. Genotypes Pat phou (G16), Malmalsang (G17), Asangbakakra (G19), ChakaoPoireiton (G11), Keibiphou (G14) and RCM-12 (G6) were near the origin hence those are stable genotypes whereas genotypes RCM-10 (G10) and RCM-11 (G18) were fell away far from the origin hence those are unstable genotypes. Sangsangba (G1) and RCM-11 (G18) specifically adapted to A4 $(100 \mu \mathrm{M}), \mathrm{RCM}-10(\mathrm{G} 10)$ is adopted to $\mathrm{A} 0$ $(0 \mu \mathrm{M})$. As per both AMMI1 and AMMI2 biplot RCM-7 (G7) and ChakaoPoireiton (G11) were stable genotypes with highest seedling dry weight.

In conclusion the AMMI1 biplot has indicated that all the aluminium levels have shown graded differences among themselves. The PC1 (IPCA1) values which are deviating from unity indicate their unstability. Thus, E3 and E4 plotting near to the point of origin have exerted less influence on the genotypic expression while E1 and E7 have exerted highest influence on the genotypic expression 
either in a positive or negative manner. Comparison with mean values have already indicated that the mean values in E7 for various characters were comparatively lowest and the values were highest in E1 which also happen to be the control. Genotypes which fall right to the mean abscissa have higher values over the mean while those on the left of the mean abscissa have lower mean hence are not desirable. Perusal of Figure 4. 1a and 4.2a indicated that genotypes RCM-6 (G2), ChakaoPoireiton (G11), RCM-12 (G6), Tungou (G3), Keibiphou (G15), CAU-R1 (G20) were in general less affected by aluminium levels, while RCM-10 (G10), RCM-5 (G9) and Sangsangba (G1) were relatively sensitive to aluminium levels.

From AMMI 1 and AMMI 2 biplots it was concluded that genotypes RCM-7 (G7), Keibiphou (G14), Pat phou (G16), RCM-4 (G4), RCM-13 (G15) and ChakaoPoireiton (G11) were near the origin indicating their non-sensitive nature to environmental forces and showed wide stability for the character seedling fresh weight. For seedling dry weight genotypes Pat phou (G16), Malmalsang (G17), Asangbakakra (G19), ChakaoPoireiton (G11), Keibiphou (G14) and RCM-12 (G6) were near the origin hence those are stable genotypes. RCM-7 is the genotype which is having high seedling fresh and dry weights over the mean and also present closely to the origin, this indicated that this is the stable genotype with high mean value.

\section{References}

Crossa, J., Gauch, H. G., and Zobel, R. W. (1990). Additive main effects and multiplicative interaction analysis of two international maize Crop cultivar trials.

Department of Agriculture, Government of Manipur. (2019).

Ebdon, J.S. and Gauch, H. G. (2001).
Additive main effect and multiplicative interaction analysis of national turfgrass performance trials. Crop Science.42(2): 497506. doi: 10.2135/cropsci2002.4970.

Farshadfar, E. (2008). Incorporation of AMMI Stability Value and Grain Yield in a Single NonParametric Index (Genotype Selection Index) in Bread Wheat. Pakistan J Biol Sci 11:17911796.

Gauch HG. Matmodel version 2.0. AMMI and related analysis for two way data matrics. Micro computer power, Ithaca, New York, USA, 1993, 59.

Gauch HG. Matmodel version 2.0. AMMI and related analysis for two way data matrics. Micro computer power, Ithaca, New York, USA, 1993, 59

Gauch, H. G. (1988). Model selection ad validation for yield trails with interaction. Biometrics, 44: 705-715.

Gauch, H. G. (1992). Statistical analysis of regional yield trails: AMMI analysis of factorial designs. Elsevier Science Publishers, Pp. 278.

Gauch, H.G. and Zobel, R.W. (1996). AMMI analysis in yield trials. In: Genotypeby-Environment Interaction. Boca Raton, New York, USA. 85-122.

Pariasca-Tanaka, J., Satoh, K., Rose, T., Mauleon, R. and Wissuwa, M. (2009). Stress response versus stress tolerance: a transcriptome analysis of two rice lines contrasting in tolerance to phosphorus deficiency. Rice, 2: 167185.

Rao, I.M., Miles, J.W., Beebe, S.E., Horst, W.J., 2016. Root adaptations to soils with low fertility and aluminium toxicity. Ann. Bot. 118, 593-605.

TaddesseLakew, Abebaw Dessie, Sewagegne Tariku, Desta Abebe. Evaluation of Performance and Yield Stability Analysis Based on AMMI and GGE Models in Introduced Upland Rice 
Genotypes Tested Across Northwest Ethiopia. Int J Agric Sci. 2017; $3(2): 17-24$.

WondeAbera and Labuschagne, M. (2005). Stability analysis of Ethiopian maize varieties using AMMI model. Ethio. J.
Agric. Sci. 18(2):173-180.

Zobel RW, Wright MJ, Gauch HG. Statistical analysis of a yield trial. Agron. J. 1988; 80:388-393.

\section{How to cite this article:}

Kanala Sai sreelekha, E. V. D. Sastry, M. Prapakaran and Danisa Dube. 2020. AMMI Analysis for Aluminium Tolerance on Seedling Parameters of Indigenous Rice Genotypes from Manipur. Int.J.Curr.Microbiol.App.Sci. 9(09): 1278-1285.

doi: https://doi.org/10.20546/ijcmas.2020.909.156 